\title{
CORRECTION
}

\section{Correction to: Editorial about PROOFS 2019}

\author{
Karine Heydemann ${ }^{1} \cdot$ Letitia $\mathrm{Li}^{2}$
}

Published online: 4 June 2021

○) Springer-Verlag GmbH Germany, part of Springer Nature 2021

\section{Correction to: Journal of Cryptographic Engineering} https://doi.org/10.1007/s13389-020-00236-5

After publication, it was noticed that the title of the article was incorrectly given as Editorial about PROOFS 2015. The correct title should read as: Editorial about PROOFS 2019.

Publisher's Note Springer Nature remains neutral with regard to jurisdictional claims in published maps and institutional affiliations.

The original article can be found online at https://doi.org/10.1007/ s13389-020-00236-5.

Karine Heydemann

karine.heydemann@lip6.fr

1 Sorbonne University, CNRS, LIP6, 75005 Paris, France

2 FAST Labs, BAE Systems, Burlington, MA 01803, USA 